\title{
Successful small group teaching
}

\author{
Anne Worrall-Davies
}

The aims of this article are to provide guidance on how to facilitate small group teaching and to address ways in which learners can be actively involved in the small group setting.

\section{How to read this article}

To make best use of this article, it is suggested that you first read the two observed teaching examples in Boxes 1 and 2. For both, just read the learning objectives and teaching plans, then jot down your own thoughts about how the teaching might have progressed, and finally read the tutor's notes and the observer's comments. Compare your own thoughts with these before reading the main article. At various stages you may wish to look again at the observed teaching examples. It is also suggested that you repeat the above exercise when you have finished reading. The multiple choice questions at the end are based on the article as a whole.

\section{What is small group teaching?}

Small group teaching is a rather broad term without a clear definition. It covers tutorials, seminars and small problem-solving classes - the size of the 'small' group may vary from a handful of students to around 30 participants. What actually goes on in small group teaching may at first sight seem rather a mystery to tutors and students alike. In fact, the small group setting provides an ideal opportunity for teachers to facilitate active learner participation.

\section{Why is learner participation desirable?}

Educational research over the past two decades has shown us that there are two clear styles of learning - 'surface' and 'deep' (Collier, 1985; Marton \& Saljo, 1976; Bligh, 1995). Surface learning involves the assimilation of material by rote learning and is the way that many of us progressed (successfully) through medical school. Deep learning involves understanding, applying and integrating new material, and is the way that many of us now (hopefully) address new clinical and research ideas. Whereas surface learning results in good immediate recall of material, deep learning sets a better longterm pattern of recalling and applying new material. An evaluation of Harvard Medical School's problembased learning approach to teaching (Moore et al, 1994) showed that students gained the same amount of knowledge as with the previous traditional programme, but they gained much more in terms of interpersonal and psychosocial skills and their enjoyment was greater.

\section{Learning and teaching in psychiatry}

For many of the psychiatric concepts and ideas that we teach undergraduates and postgraduates, deep learning would, therefore, be a desirable learning style for students. Although the teaching methods discussed later in this article can promote deep learning (see Boxes 3 and 4), it should be remembered that for some students, surface learning is the more natural method, and many may attempt to

Dr Anne Worrall-Davies is Senior Lecturer in Child \& Adolescent Psychiatry at the Academic Unit of Child \& Adolescent Mental Health, 12A Clarendon Road, Leeds LS2 9NN. Her clinical and research work is centred on paediatric liaison. She has an interest in promoting reflective and innovative teaching practice in undergraduate and postgraduate education. 
convert interactive sessions into fact-gathering sessions because this feels more comfortable. You yourself may be a natural surface learner, making teaching styles aimed at promoting deep learning inherently more difficult for you. For those of you who are naturally deep learners, you may be desperate to throw away the fact-informing lecture notes of past years - however, lectures also have considerable merit if well-structured and presented (Sensky, 1999). Remember that there are a variety of styles and techniques you can use (Boxes 3 and 4) reflect carefully on which might best suit you, your material and your students.

\section{Reflection, evaluation and observation}

A caveat to using a variety of teaching methods in one session is not to get over-enthusiastic and leave yourself and students unsure whether the session is a psychiatry teaching or a crash-course in innovative teaching practices! The best way to avoid such mistakes is through self-reflection, student evaluation and peer observation of teaching

Box 1. Observed teaching example 1

Time: 1 hour

Students: MSc/MPhil course in psychiatry

Topic: Normal infant development, $0-2$ years

Learning objectives: At the end of the teaching, students will:

- be able to list key motor, sensory, cognitive and psychosocial maturational tasks for this developmental period

- have an understanding of the relations between each of these tasks

- be aware of appropriate theoretical frameworks for these developmental tasks

Teaching plan:

Introductions, tutor and students

Map out session structure for students

Brainstorm developmental tasks for 0-2 year olds and collate

into theoretical framework (Eriksen, 1965)

Introduce live baby into session

Students buzz group to guess baby's age

Students to suggest ways of checking out age and doing

developmental tests (some equipment available) $20 \mathrm{mins}$

Students brainstorm baby's age again

Conclusions and final questions

5 mins

5 mins

10 mins

5 mins

5 mins

10 mins

\section{Observer's comments:}

Clear teaching plan with original idea of live baby - this was received very well by students! Could not easily be repeated, though, and could have fallen apart if baby had become distressed (contingent plans were available, apparently). The obvious positives were the immediate studentstudent interaction generated by the buzz groups/brainstorms and by the 'live demo' of the baby. Developmental testing was said to be 'fun' by several students instead of 'boring' as perceived previously. Lots of questions were asked at the end.

\section{Teacher's own reflection:}

Seemed an ideal opportunity to combine new motherhood and teaching child development. Did have other plans if baby had not cooperated - I think it worked well because I knew I had Plan B so felt relaxed about it all. Not repeated easily but I have video footage of all developmental stages of baby so could revamp next time with annotated video clips. It was a lively session, though, and I might consider 'borrowing' a baby for a repeat session! 
sessions. Evaluation will be dealt with in another article in this series. Self-reflection and peer observation are discussed here. All clinicians are used to reflecting on the content and process of clinical sessions, and it is only a matter of habit to reflect on the content and process of a teaching session. Being a 'reflective teacher' uses the same skills as being a good clinician. Why did it seem to go badly after a good start? What could I have done to encourage the students to talk more ? What can I do next time to avoid running over time? A useful framework might be:
- What went well and why?

- What went badly and why?

- What could I do to improve next time?

More detail, outside the scope of this article, can be found in Brown \& Atkins (1988).

Peer observation is another important way of assessing your performance as a teacher. It does not have to be threatening, and probably most of us actually perform better than we think we do. Setting up a group of colleagues to sit in on each others' teachings is a non-threatening way of organising peer

Box 2. Observed teaching example 2

Time: 2 hours

Students: MSc/MPhil course in psychiatry, 20 students

Topic: Depressive disorder in children

Learning objectives: At the end of the teaching, students will be able to:

- describe the frequency and distribution of depressive disorder in childhood

- compare and contrast aetiological factors of depression in children and adults

- defend the proposition that psychological therapies are the first-line treatment for childhood depression

- briefly describe the principles of the therapies available and evaluate the evidence for their effectiveness

- make predictions about which children are likely to go on to have depression in adulthood

Teaching plan:

Introductions, tutor and students

5 mins

Map out session format for students

5 mins

Syndicate method (see Box 3) : five groups of four students to work on tasks directly drawn from the five learning objectives; material provided in room (books, relevant key papers)

Five group presentations with discussion

Conclusions and final questions

60 mins

45 mins

5 mins

Observer's comments:

Clear teaching plan with use of syndicate method - this was received with caution by students, but they warmed to the tasks. The obvious positives were that the majority of the session was spent in student-student interaction and student-led discussion with the tutor.

Teacher sounded a little nervous at the start but this did not last long. Students picked up on this and may have attributed it to teacher being observed - seemed to want to help him as a result, empathised with him.

Teacher's own reflection:

Was not too sure whether this would work and I do not think I presented it with a great deal of confidence. I thought the students might rebel, refuse to do the task or sabotage it. I had tried to plan it carefully, with thought about what I would do if it did go wrong and how I would respond if the students did sabotage it. I felt uncomfortable and guilty that I was perceived as not doing much while they were working hard at the tasks - in fact, I spent the majority of the time in discussion with the students. The students asked questions I am sure they would not have asked in a big group. Varying levels of questioning, from basic concepts to sophisticated level, challenging my own knowledge base. I developed a different type of relationship with the students - more of a peer relationship, less of hierarchical teacher-pupil one. By the end, this felt good, but initially I felt rather out of control. 
Box 3. Some good methods of small group teaching

Case discussion Presentation of case followed by group discussion. Stated aim of the teaching session to solve a problem in the group discussion

Buzz group Brief, 1-2 minute discussion of a clear question or topic, in pairs. Ideas generated fed back and discussed by whole group

Syndicate Mini-project work done by individuals or 2-4 students together, reported back to the whole group

Brainstorming Rapid idea generation from whole group. Ideas received with no criticism by tutor and collated. Discussion and evaluation of collated ideas by whole group

Role-play

Small groups of students act out vignettes - some students may play observers of the role-play, leading to discussion by whole group

Fishbowl

Small group, 2-4 students discuss or present topic in front of remainder of group who watch and then discuss. The small group then act as observers to the remainder of group who re-present the topic

Rounds

Each participant talks in turn

Pyramids

Start in pairs, then work in groups of four, then 8 , then 16 , etc. until whole small group involved in task

NB Prior to looking at Box 4, try thinking of examples for each teaching method from your own practice

Box 4. Examples of good practice in small group teaching in postgraduate psychiatry

Case discussion Case presentation of 17-year-old Asian boy with psychotic symptoms, diagnosis uncertain. Stated aim of the teaching session to formulate a working diagnosis

Buzz group Topic: introduction to psychological problems in children. Asked to spend two minutes in pairs listing diagnoses likely in children. Diagnoses generated fed back and discussed by whole group

Syndicate

Mini-project work done by groups of four and reported back to the whole group: what is different between the presentation, treatment, outcome of depression in children and in adults?

Brainstorming Generation of probable aetiological factors for major depressive disorder from whole group. Ideas received with no criticism by tutor, and collated in framework of 'biological', 'social' and 'psychological' factors prior to whole group discussion

Role-play

Small groups of students act out vignettes of family of teenager with anorexia nervosa

Fishbowl

Small group, 2-4 students discuss or present topic in front of remainder of group who watch and then discuss. The small group then act as observers to the remainder of group who re-present the topic

Rounds Topic: research methods. Each participant briefly describes own research experience and particular strengths and weaknesses

Pyramid

Topic: use of Mental Health Act. Discuss in pairs when, and how appropriately, participants have used Sections 2 and 3 in cases of life-threatening anorexia nervosa, then build up through pyramid to whole group discussion 
observation. It is also useful to ask the observer to answer specific questions about the teaching, or to do focused tasks, such as timing the proportions of a session in which you and the students are talking.

\section{What makes a good small group teacher?}

First and foremost, a good small group teacher facilitates communication between students, and between students and their teacher. Tutor interventions can be usefully divided (Brown \& Atkins, 1988 ) into authoritative (prescriptive, informative and confronting) and facilitative (cathartic, analytic and supportive). Authoritative interventions tend to shut down dialogue in teaching sessions, whereas facilitative ones encourage dialogue. Most psychiatrists will be accustomed to using facilitative interventions in client sessions, particularly if using a client-centred model (Rogers, 1961). To be good facilitators of communication, small group teachers need excellent questioning, listening, responding and explaining skills.

\section{Questioning, listening and responding}

Questions may be asked to gather information, explore feelings and attitudes and encourage thinking - see Box 5 for a useful classification.

Recall questions expecting a factual answer may be inherently threatening as they expect a correct response. Open questions inviting observations and thoughts are likely to open up a session for students

Box 5. Types of questions

Recall-observation-thought, divided as to whether the question elicits a recalled fact, encourages an observation on a topic, or invites a discursive comment

Open or closed, inviting an extended response or a yes-no answer, respectively

Encouraging-threatening, respectively providing and preventing a safe enough environment for an answer to be attempted

Clear-confused: confused questions have more than one question embedded in them, or are ambiguous to join in, with little expectation of correct and incorrect responses. How do we judge whether our questioning is clear, encouraging and open enough to facilitate discussion? Self-reflection after the session is useful - videotaping sessions, or having a peer observer there, are also ways of analysing questioning in detail. The observer might count the number of each type of question, or might record the student responses to different types of questions.

Listening and responding to students is very similar to listening and responding to a client. It is important to be able to show the students that you are actively listening to what is being said - nonverbal signs are useful, as are prompts, and encouraging ' $\mathrm{mm}-\mathrm{mm}$ ' sounds. For further thoughts on questioning, listening and responding to small groups, try Brown \& Atkins (1988) or psychotherapy texts to refresh your knowledge of client-based skills (e.g. Rogers, 1961; Casement, 1985).

\section{Further information}

Most of the essential features of planning and structuring a small group teaching have been covered in the other articles in this series on teaching in psychiatry (Sensky, 1999) and in a previous series of articles (Curran \& Bowie, 1998; WorrallDavies,1998). Some additional useful reading material has been listed at the end of the article.

\section{References}

Bligh, J. (1995) Problem-based, small group learning. British Medical Journal, 311, 342-343.

Brown, G. \& Atkins, M. (1988) Effective Teaching in Higher Education. London: Methuen.

Casement, P. (1985) On Listening to the Patient. London: Tavistock.

Collier, K. G. (1985) Teaching methods in higher education: the changing scene with special reference to small group work. Higher Education Research and Development, 4, 3-27.

Curran, S. \& Bowie, P. C. W. (1998) Teaching psychiatry to medical undergraduates. Advances in Psychiatric Treatment, 4, 167-171.

Eriksen, E. (1965) Childhood and Society. Harmondsworth: Penguin.

Marton, F. \& Saljo, R. (1976) Approaches to learning. In The Experience of Learning (eds F. Marton, D. Hounsell \& N. Entwhistle). Edinburgh: Scottish Academic Press.

Moore, G. T., Block, S. D., Style, C. B., et al (1994) The influence of the new pathway curriculum on Harvard medical students. Academic Medicine, 69, 983-989.

Rogers, C. (1961) On Becoming a Person. Boston, MA: Houghton Mifflin.

Sensky, T. (1999) Giving presentations. Advances in Psychiatric Treatment, 5, 317-320.

Worrall-Davies, A. (1998) Teaching psychiatry to medical undergraduates: child \& adolescent psychiatry. Advances in Psychiatric Treatment, 4, 172-176. 


\section{Further reading}

Jaques, D. (1991) Learning in Groups. London: Croom Helm. Bligh, D. (1986) Teach Thinking by Discussion. Windsor: NFERNelson.

Schon, D. A. (1987) Educating the reflective practitioner. San Francisco, CA: Josey Bass.

\section{Multiple choice questions}

1. In generating ideas using the brainstorming technique, it is important for the teacher to:

a follow up the ideas later in the session with the students

b not to mention to students beforehand that the ideas generated will be used later in the session

c constructively criticise the ideas as they are generated

d collate the ideas as they are generated using a useful framework.

2. When lecturing in the small group setting, the teacher should:

a break the session up into mini-lectures, each with a beginning, middle and end

b allow plenty of opportunities for questions to be asked

c not allow interruptions

d take the opportunity to present his or her own up-to-date research work.
3. The most important skills for the small group teacher to possess are:

a the ability to listen actively

b the ability to interrupt to keep the session on course

c the ability to reflect on his or her own teaching practice

d the ability to make appropriate dynamic interpretations of students' contributions.
MCQ answers

1

a $\mathrm{T}$ a $\mathrm{T} \quad$ a $\mathrm{T}$

b F b T $\quad$ b F

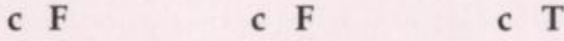

$\begin{array}{lll}\text { d } T & \text { d F } & \text { d F }\end{array}$

\section{Visit the Royal College of Psychiatrists web site at http://www.rcpsych.ac.uk}

\section{Information on:}

- press and public initiatives

- conferences

- college books and journals

- examinations

- postgraduate education

- the College Research Unit
And for members:

information on divisions, faculties, sections, SIGS, committees and more

For further information, please e-mail: lalexander@rcpsych.ac.uk 